\title{
Decline of Insects: Is dust emission conflicting with insects' tracheal system?
}

\author{
Ulrich Thurm ${ }^{1,2}$ \\ Institute for Neuro- and Behavioral Biology, University of Münster, Münster, Germany
}

\section{Summary}

Is the extensive decline of insects partially due to an insect-specific feature of their functional organization that is disadvantageous for living in an industrialized environment? The unique way in which gases are supplied in insect tissues is such a special trait. It exposes cells directly to the gas phase, via tracheae that end in micro-tubes, the tracheoles, which have diameters in the same range as particles of ultra-fine dust transported by air of industrialized countries. Number and volume of these particles - calculated to be inhaled by honeybees, e.g., - are indicative to locally impede $\mathrm{O}_{2}$ uptake and $\mathrm{CO}_{2}$-release and thus to restrain physiological activities.

Keywords: Insect decline, Tracheal system, Tracheole, Fine dust, Ultrafine particles

\section{Introduction}

Since the last decades of the last century, a decline of European insects is subject of concern. It has been recorded systematically and in detail e.g. for British macro-moths (337 species observed for 35 years, 1968 to 2002: Conrad et al., 2006) and for total flying insects in 63 nature protection areas of western and eastern Germany for 27 years (1989-2016: Hallmann et al., 2017). The British macromoths were recorded with respect to their diversity: Two third of the 337 species of southern Britain declined by up to $50 \%$ of individuals per decade. In 63 nature protection areas of Germany, the abundance of all flying insects was recorded and found declining by $76 \%$ within 27 years. More recently, the populations of insects were studied within 150 grassland and 140 forest areas of 3 regions of middle and southern Germany, using comprehensive data recording (Seibold et al., 2019). This study found and characterized decline with respect to the diversity as well as to the abundance of insects, revealing $78 \%$ decline of abundance in 9 years. The beginning of a decline was observed at East-Bavarian moths in the years around 1980 by Reichholf, when he recorded their abundance from 1969 up to 2016 (Reichholf, 2017) and found decline by about 75\% within 15 years. 2019, in an international compilation, Sánchez-Bayo and Wyck-huys demonstrated the worldwide relevance of the decline of insects (Sánchez-Bayo and Wyck-huys, 2019).

Spiders, as well as numerous species of birds, amphibians and reptiles are also disappearing in recent decades. They largely depend on insect prey; their disappearance is understood, at least in part, as a consequence of the disappearance of insects (Seibold et al., 2019).

Efforts to find the causes of the decline of insects, i.e. its drivers, indicated that the causes could not be found in the immediate vicinity of the biotopes under study. Fox et al. (2014) suggested that changes of land use and climate are major drivers of the loss in moth biodiversity. Seibold et al. (2019) specified that insect decline was independent of local land use intensity and suggested "that major drivers are associated with agriculture at the landscape level". Hallmann et al. (2017), studying areas under nature protection, "showed that ... changes in weather, land use and habitat characteristics cannot explain the insect decline".

The processes considered to cause insects' decline obviously take place; however, they hardly explain the widespread distribution of decline, as well as its roughly exponential time course during several decades at constant sites (Conrad, 2006; Hallmann et al., 2017; Seibold et al., 2019). Moreover, they

\footnotetext{
1 *For correspondence: thurmu@uni-muenster.de 22ORCID: https://orcid.org/0000-0002-9021-0778 Funding and competing interests: The author declares that no funding or competing interests exist.
} 
hardly explain the astonishing parallel decline in orders and populations of insects that are subject to substantially diverse ecological conditions and needs, such as houseflies, mosquitoes and moths in urban areas, ants and moths in gardens and woodlands as well as crickets in heathlands (popular Central European observations).

From existing and missing correlations of the decline of species may be deduced: The most widespread, serious and amazing commonality of the processes of decline is hardly found in agricultural relationship, but - seemingly trivial - in the identity of the animal class concerned: The decline occurs as a decay of the number of individuals of many or most species of the class of insects living in a common area, without common specialties of ecological needs.

This suggests that a kind of driver of decline is acting that does not attack special needs of special species of insects, but attacks needs that are specific for the class of insects on the whole.

\section{Question:}

Could the decline of insects be linked to a physiological peculiarity of insects that is specific to this particular class of animals, but is incompatible with some ecologically widespread factor that has occurred in recent decades, possibly a product of recent technical developments?

Insects, owning a system of tracheae and tracheoles, do indeed possess a physiological organization that characterizes these animals, distinguishing them from almost all other animal classes (including other arthropods) and contributes pronounced physiological consequences. It supplies the required atmospheric oxygen to the metabolically active cellular tissue directly in the gas state, not - as in other animal classes - in a state chemically bound to a protein, the blood pigment.

As a serious physiological implication of this tracheolar gas transport, not only the respiratory gases but also the entire gas phase is directly or almost directly transported to all metabolically active cells, including the cells of the sexual organs. The gas phase is separated from these cells only by diffusion paths in the micrometer or sub-micrometer range, without interposed buffering and filtering fluid volumes. There is no oxygen-transporting medium available that - like the blood of vertebrates would select the gases to be carried and would keep off fine dust. Based on the tracheal principle, airborne pollutants have direct access to the cells of all organs of all functions. If the breathing air carries particulate pollutants (fine dust), they can be randomly distributed to individual organs or parts of organs.

Insects are therefore more vulnerable to airborne pollutants than members of other animal classes living in air. While insects' tracheal system is fundamentally known to biologists since long, the purpose of present study is to examine to what extent its organization bears actual risk, a risk that could contribute essential causation for insects' actual decline. Studies to be conducted on this issue may allow targeted experimentation and reliable identification of causes of decline, supporting their appropriate control.

\section{Characterization of tracheoles and potential risk for respiration}

The particular risk exists in the supply lines of the gas phase near to the tissue, the tracheoles, and their transition to the cells of the tissue. In the bigger main tracheae, in contrast, the flow of air appears unproblematic. The air passes through their special opening structures, the stigmata (diameter approx. $10 \mu \mathrm{m}$ ), into and out of the body and communicates within the body. Air currents are caused by the movements and contractions of the body, i.e. by pressure gradients. These tracheae, just as the outer body wall, are lined with a chitin cuticle which gets renewed (shed) together with the outer cuticle (see Harrison, 2009; Wigglesworth, 1983, 1984).

The supply and drain of respiratory gases from the tracheae to and into the individual organs, in contrast, occur via the tracheoles, formed by special tracheole cells (tracheal terminal cells). Their 
tubes are located directly at or within the cells to be supplied; most important: they are terminally closed. Chitin lining vanishes within these segments; their tube wall tends to be reduced to the cell membranes that are in tight contact with the membrane of the supported cell. Within the tracheoles, the molecular fluxes are based on the concentration gradients that dynamically occur for the respective gases. They arise as gradients between the local concentrations (partial pressures) of the respective gas in the outer airspace, on the one hand, and the local concentration (partial pressure) of this gas within the end section of the tracheole, on the other. This local partial pressure of the individual gas results from the binding or release of molecules of this gas at the tracheole membrane and from the entry and passage of its molecules through the luminal and basal membranes of the tracheole. Although the tracheoles are morphologically blindly closed, the concentration gradients allow net inward and outward flows for different substances simultaneously at the same location, but - in this basic scheme - no volume flow that would push particles in or out.

It can be assumed that this principle applies equally to molecules of all kinds that adhere or bind to the tracheole membrane - regardless of whether the molecules sooner or later pass through the tracheole membrane and diffuse within a cytoplasm (like $\mathrm{O}_{2}$ ) or whether they remain bound in or at the membrane. Since molecules that have become immobile by binding at the tube membrane no longer reduce the "steepness" of their diffusion-concentration gradient, growing accumulations are conceivable in the tracheoles for individual species of molecules.

For sufficient oxygen uptake and carbon dioxide release of the tissue to be supplied, a high surface/volume ratio of the blindly closed tracheoles is essential. Extensive branching and minimum diameters of the terminal tracheoles increase this ratio. The inner diameters of the terminal tracheoles - 0.1 to $0.5 \mu \mathrm{m}$ - are slightly larger than the "free path lengths" of the Brownian motion of the gas molecules in air (Biserova and Pflüger, 2004; Sauerwald et al., 2019). For these molecules just as for other airborne molecules and molecule complexes - therefore high probability exists for multiple contact with the tracheole membrane. The end sections of the tracheoles are filled either with liquid or with air, depending on the oxygen demand of the surrounding tissue (Wigglesworth, 1983,1984 ; see below). The reversibility of the air or water occupation of the inner surface, in spite of the small diameter of the capillaries, suggests similarly strong hydro- and lipophilicity (= amphiphilicity) of the tracheole membrane.

This design of gas exchange includes a serious disadvantage as soon as the air to be breathed contains toxic substances that adhere to, penetrate or permeate the tracheole membrane, such as polycyclic aromatic hydrocarbons (PAH). They are more fat-soluble than water-soluble. It is to be expected that molecules of such (hazardous) substances enter the lipid phase of the tracheal membrane - independent of the function of the organ supplied by these tracheoles (Herrenbauer, 2002).

Muscle activity of the animals increases the exchange of the respiratory gases in the tracheal tubes and thus also replenishes airborne pollutants at the entrance of the tracheoles. This leads to accumulation of the pollutant molecules when they bind to or pass the tracheole membrane. It can therefore be assumed that (e.g.) airborne hydrocarbon particles are taken up in the tracheal system in proportion to the uptake of oxygen molecules, and a high percentage of them are adsorbed by or pass through the tracheolar membrane. While the $\mathrm{O}_{2}$-molecules fire the vital metabolisms and the energy metabolism of the cells following their diffusion in the tissue and are released again by the organism in the form of $\mathrm{CO}_{2}$ and $\mathrm{H}_{2} \mathrm{O}$, the tracheal-tracheole system probably works like an accumulating filter for exogenous vapor or gas molecules and ultra-fine dusts. Also, the air/water exchange observed within the tracheolar terminal routes (see below) probably does not lead to a removal of hazardous substances, that would correspond to the "rinsing" process in trachea and lung of vertebrates, where mucus continuously moves across the gas-exchanging tissue-surfaces and will 
be eliminated. In contrast, the tracheoles run the risk to operate like air filters that are never cleaned but accumulate all dust experienced over lifetime.

The hazard potential, that is special for the tracheal system, arises from airborne molecular aggregations, not from gaseous hazardous substances such as oxides of nitrogen and carbon which diffuse more easily in the body tissue and are less capable of accumulation. Of these gases, no other risks are known for insects than those known for mammals. Therefore, effects of gaseous oxides of nitrogen and carbon are not considered here.

Larger, multimolecular particles (ultrafine dust particles, see below), that enter the tracheae in the volume flow of air described above, can be shifted into the tracheoles by two types of processes:

a) by deformations of the tracheoles by adjacent contractile cells, in particular muscle cells;

b) by the above-mentioned reversible filling of the tracheole lumen with aqueous liquid from its terminus (Wigglesworth 1983, 1984). If there is lack of oxygen in the surrounding tissue, this liquid gets absorbed and draws air into the tracheole together with the particles it contains (see below for more).

\section{Material hazardous to tracheal systems}

Standard air has an "aerosol" character due to the formation of molecule complexes. It is characterized by

- coagulation of airborne molecules into multimolecular particles ("ultrafine dust") and into particles ("fine dust"),

- particles floating for days, possibly transported over hundreds of kilometers,

- condensation of vapor molecules on existing particles,

- evaporation of molecules from particles.

Aerosols are described, on the one hand, physically: by weight, volume and size of the individual particles and their complexes; on the other hand, chemically: by the composition and concentrations of their components. With regard to particle sizes, 2-3 classes are distinguished:

- Ultrafine particles (UFP, particulate matter PM 0.1): airborne particles with a diameter between 10 and 100 nanometers (diesel soot: particle diameter 20-35 nm). They are widely distributed in the atmosphere in number concentrations of 1000 to 8000 particles $/ \mathrm{cm}^{3}$ (Birmili et al., 2018).

- Particulate matter (PM2.5 and PM10): defined by the aerodynamic particle maximum diameters <= $2.5 \mu \mathrm{m}$ and $<=10 \mu \mathrm{m}$, respectively; it consists, particularly, of combustion products of fossil fuels from road and air traffic, heating chimneys and some industries, as well as ammonia derivatives derived from agriculture (Bruckmann et al., in Schmidt K G, Zellner R, 2010; Federal Environment Agency: Particulate matter pollution). The limit value for air pollution with particulate matter PM10, set for the protection of human health in Germany, is $40 \mu \mathrm{g} / \mathrm{m}^{3}$, for particulate matter PM2.5 it is 25 $\mu \mathrm{g} / \mathrm{m}^{3}$. In the 1990s, PM10 emissions were almost twice as high as they are at present.

\section{Flight of fine dust}

Fine dust particles PM2.5 fly for up to 5 days; smaller and larger particles fly for shorter time (Bruckmann et al., in Schmidt K G, Zellner R; 2010). Corresponding transport distances are $30-200 \mathrm{~km}$ at wind speeds of $3 \mathrm{~m} / \mathrm{s}$, several $1000 \mathrm{~km}$ at higher wind speeds. Thus, the local concentrations of fine dust are determined by the activity of widely distributed sources.

Probably, particles of all classes of fine dust enter insect tracheae at their stigmata by active and passive respiratory flow of air and are distributed in the wide lumen of the cuticle-lined tracheae. Those particles with a diameter of $>1 \mu \mathrm{m}$ cannot be assumed to enter the tracheoles. Obstructions of flow and diffusion in tracheae and closing of tracheoles may happen. Also, disintegration of such particles into physiologically effective smaller particles and molecules might occur. Such particles - 
ultrafine dust (10-100 nm diameter) and complexes of gas-molecules - might enter the tracheoles (100-300 nm diameter), participate in diffusion until they remain stuck.

\section{Method for estimating inhaled quantities of hazardous substances:}

The amount of airborne substances that insect individuals take up in defined periods of time can be estimated from the concentrations of these substances in air and from the measured volume of oxygen inhaled by the animal, taking into account the standard proportion of oxygen in air (21\%). It has to be considered that the $\mathrm{O}_{2}$-uptake of these animals strongly depends on their motor activity, in particular during flight: Constant flight activity in bees resulted in about 50 times higher $\mathrm{O}_{2}$-uptake than behavior without flight activity (Jongbloed and Wiersma, 1934).

With a medium level of flight activity, similar values of $\mathrm{O}_{2}$-uptake per body mass $(\mathrm{kg})$ and time (hour h) were found in different insect classes:

- Honey bee worker: 45 liters $\mathrm{O}_{2} / \mathrm{kg}^{*} \mathrm{~h}$ (Jongbloed and Wiersma, 1934; Wigglesworth, 1984)

- Locusta migratoria: 10-30 liters $\mathrm{O}_{2} / \mathrm{kg}^{*} \mathrm{~h}$ (Butler and Innes, 1936)

- fruit fly Drosophila: 21 liters $\mathrm{O}_{2} / \mathrm{kg}^{*} \mathrm{~h}$ (Chadwick and Gilmour, 1940).

From the minimum volume of air inhaled and the concentration of the hazardous substance of interest in standard air one may estimate the quantity of the hazardous substance absorbed by the average individual animal per observed period of time.

\section{Estimation of inhaled quantities of airborne hazardous substances}

All three fractions of dust (PM0.1; PM2.5; PM10) contain similar proportions of organic material (15$20 \%$, mainly PAH, see below) and ammonia (approx. 10\%) (Herrmann et al., in: Schmidt K G, Zellner $R, 2010)$. Substances of both groups can be considered to be hazardous for the tracheolar system, also the physically defined ultrafine particles:

a) Polycyclic aromatic hydrocarbons (PAH) and their nitro-derivatives are suspended solids and gas molecules that are carcinogenic and mutagenic in vertebrates (Eikmann et al., in: Schmidt K G, Zellner $R, 2010)$. The mean content of the representative substance benzo(a)pyrene (B(a)p; molecular weight $252 \mathrm{~g} / \mathrm{mol}$ ) in German standard air is $0.5 \mathrm{ng} / \mathrm{m}^{3}$ (depending on location; according to German Fed. Envir. Agency 2017: B(a)p: 0.05-1.5 ng/m³ ; European "target value" $1 \mathrm{ng} / \mathrm{m}^{3}$ air). Absorbed amount of substance - model calculation:

1 honeybee worker receives approx. $3.1 * 10^{8} \mathrm{~B}(\mathrm{a}) \mathrm{p}$ molecules per day at about $50 \%$ flight activity in 10 collection hours/day, in a collection period of 10 days approx. $3.1 * 10^{9} \mathrm{~B}(\mathrm{a}) \mathrm{p}$ molecules.

b) Ammonia $\left(\mathrm{NH}_{3}\right)$, present as gas molecules and molecule complexes, is easily soluble in water, shows an alkaline reaction, forming the ammonium cation $\mathrm{NH}_{4}{ }^{+}$. This is neurophysiologically toxic due to its similarity to the $\mathrm{K}^{+}$-ion. Standard concentration of ammonia in German air is $1-10 \mu \mathrm{g} / \mathrm{m}^{3}$; it remained unchanged since 1990 until today and originates almost exclusively in agriculture (German Fed. Envir. Agency).

Absorbed amount of substance - model calculation:

1 honeybee worker receives at $3 \mu \mathrm{g} \mathrm{NH} / \mathrm{m}^{3}$ air and 50\% flight activity in 10 days with 10 collection hours/day: about $0.45 \mathrm{nmol} \mathrm{NH}_{3}$.

c) Ultrafine particles (UFP; PMO.1; diameter $<10-100 \mathrm{~nm}$ ) are hazardous substances not only as carriers of the above-mentioned and further toxic substances, but also as centers of aggregation of suspended matter, narrowing or sealing tracheoles.

Depending on the geographical region, the annual mean concentration of PM0.1 particles in Germany is between $1^{*} 10^{3}$ and $8 * 10^{3}$ particles $/ \mathrm{cm}^{3}$ air (Birmili et al., 2018).

Absorbed quantity of substance - model calculation: 
1 honeybee worker receives approx. $1.02 * 10^{6}$ particles/day at 4000 particles $/ \mathrm{cm}^{3}$ air and $50 \%$ flight activity in 10 collection hours/day; i.e. in a collection period of 10 days approx. $10^{7}$ particles.

\section{Potential fate and effect of inhaled hazardous substances in insects}

Due to adhesion of particles within the tracheoles and their unidirectional entry, a net backward move seems unlikely. Displacements of substrates within tracheoles tend to be asymmetric processes as discussed above and below. An accumulation of ingested substances in tracheoles and in their vicinity for lifetime seems likely. Cleaning mechanisms or regenerations of inactivated tracheoles were not found.

For spatial distribution of inhaled pollutants, it is crucial that the substances in the aerosol are predominantly concentrated in molecular complexes (Herrmann et al., 2010, in: Schmidt K G, Zellner $\mathrm{R}$ (2010)). They might form "focal" aggregations with limited spatial extension in the tissue. Therefore, it seems realistic to relate the quantities of absorbed pollutants to relatively small volumes of tissue, in the order of few cells, when calculating their resulting concentrations. Little is known about the special nature of the tracheole membrane and its contact to an adjacent or surrounding cell.

\section{a) $P A H$}

PAH molecules enter lipid membranes, accumulate in the region of the head groups of the lipid molecules (Herrenbauer, 2002), and possibly enter neighboring membranes. According to findings in Drosophila, however, membranes and cellular processes of insects react to these substances less than cellular processes of mammals (Würgler et al., 1986). Effects of airborne PAH in insects may remain negligible also since the number of $\mathrm{PAH}$ molecules picked up is small.

\section{b) NH3:}

Ammonia deserves special attention with regard to the considerable dose that, e.g., a bee worker accumulates in the course of its collection period in ordinary German air: approx. $2.7 * 10^{14} \mathrm{NH}_{3}$ molecules (approx. $0.45 \mathrm{nmol} \mathrm{NH}_{3}$ ) in 10 collection days in standard air. But most parameters that would decide on damaging are unknown, notably the spatial distribution and the corresponding levels of concentration of $\mathrm{NH}_{4}{ }^{+}$that is randomly produced in various tissues:

If $0.45 \mathrm{nmol} \mathrm{NH}_{3}$ were evenly distributed across the entire cellular tissue of a honeybee (by guess $1 / 3$ of the body mass of the animal, i.e. $30 \mathrm{mg}$ ), the tissue would receive an average additional concentration of $15 \mu \mathrm{mol} / \mathrm{l}$. This might not be relevant physiologically. If, on the other hand, this amount of ammonia would be collected in, e.g., 100 tracheoles and dissolved only in their environment, each in a volume of $(10 \mu \mathrm{m})^{3}$, each of these 100 volumes would get a concentration of $4.5 \mathrm{~mol} / \mathrm{l}$ : certainly, strongly cell-damaging.

Even for significantly weaker local $\mathrm{NH}_{3}$-accumulations within the tissue, it is uncertain which effects and consequences it would produce and whether it would be degraded by $\mathrm{NH}_{3}$-metabolism. Termites and fly larvae are highly tolerant to surrounding ammonium concentrations (Marshall and Wood, 1990; Weihrauch et al., 2012; Borash et al., 2000). One must doubt, however, that this tolerance to external environment also applies to inter- and intracellular $\mathrm{NH}_{4} \mathrm{OH}$-concentrations and also to other insect species.

c) PMO.1 particles as mechanical entities:

As a component of the ambient air, PM0.1-particles get sucked into the tracheal trunks. No continuous effect, however, is noticeable that might convey such particles into tracheoles, whose inner diameter is in the range of the outer diameter of PM0.1. (Due to the multimolecular size of the particles, their thermal movements are small. Thus, concentration gradients contribute little to their distribution within tracheae and tracheoles.) However, flow of air in the tracheal trunks and passive movements due to nearby muscular activities can cause the particles to enter the branches of 
trachea and tracheoles. Arriving within a tracheole, such particle reduces the cross-section of flow and impedes the exchange of respiratory gases. As observed and explained by Wigglesworth, a local reduction of respiration causes liquid removal from the tracheole (Wigglesworth, 1983): As soon as a deficiency of oxygen occurs, the liquid that fills the terminal sections of tracheoles in their aerated state is resorbed from the tracheoles by osmotically effective metabolic processes and becomes replaced by air. This means suction of air into the tracheal trunk, acting on particles as an upward pulling and pushing flow of air. A resulting shift of the particles into the narrowing tube tends to produce a further reduction of its cross-section, up to mutual blocking of supply of air and displacement of particles in positive feedback.

Probably, such a process irreversibly impedes the exchange of respiratory gases and causes hypoxia, reducing the functional performance of this organ in the area of that tracheole.

To illustrate probability and consequences of such hits for a representative insect - a honeybee worker - the number of PM0.1 particles inhaled in flights of 10 days is considered. As in above evaluation of $\mathrm{NH}_{3}$-distribution, $30 \%$ of the body weight of the bee (=30 mg per bee worker) is assumed to represent cellular tissue and is imagined consisting of functional units of $(10 \mu \mathrm{m})^{3}$, resulting in $3^{*} 10^{7}$ cellular units per bee. If the $10^{7} \mathrm{PM} 0.1$ particles calculated to be inhaled by the bee (see above) and if these particles were evenly distributed, approximately each third of all units would gather one particle and might get at risk.

According to this estimate, PM0.1 fine dust of continental air poses real risk of impairment to insects. Tracheole blocking processes may occur randomly to any kind of organ, "silencing" an increasing number of functional areas. Thus, an insect with increasing age may possess less and less functional capacity of its organs. The individual time course of this efficiency loss is determined by the regionally and temporally fluctuating concentration of ultrafine particles in the regional air and by the individual energy expenditure.

In addition to this insect-specific risk of PM0.1-particles, human cytology indicates that such particles are able to penetrate cytomembranes and cause intracellular disturbances (Eikmann et al., in: Schmidt K G, Zellner R, 2010), an effect likely not specific to vertebrate cells.

\section{Categories of conceivable impairments by fine dust:}

- Selective, gradually progressive hypoxia (asphyxiation) of regions of organs,

- biochemical damage to cellular activities,

- hypoxic or other damage to reproductive processes;

- reduction of activity, efficiency or vitality of individuals,

In summary: reductions in the rate of reproduction.

\section{Conclusion I:}

- Insects in today's industrialized countries likely receive airborne pollutants in their tracheal system.

- Even small amounts of fine dust inhaled in this system may endanger individual insects.

\section{Consequences for insects living in fine and ultrafine dust:}

\section{- Is decline of insects correlated with spatial distribution of fine dust? ${ }^{2}$}

The findings on decline of British moths, mentioned initially (Conrad et al., 2006; Fox et al., 2013; Fox et al., 2014), in detail were correlated with the geographical location of the moths: Their abundance decreased in southern Britain by $40 \%$ of individuals (some species changed), while no significant

\footnotetext{
${ }^{2}$ Only few data exist on particle number concentrations of ultrafine dust UFP (size $<=0.1 \mu \mathrm{m}$ ), resp. PM0.1, recorded in particle number $/ \mathrm{cm}^{3}$ air. Therefore, considerations mainly refer to data of PM2.5, recorded in $\mu \mathrm{g} / \mathrm{m}^{3}$.
} 
change of abundance - no decline - occurred in northern Britain (some species changed). The zone of transition between these different regimes of abundance was denoted by the axis Lancaster-York, about $54^{\circ}$ latitude (Conrad et al., 2006; Fox et al, 2013). Asking for causal correlates of this transition, one finds a prominent gradient in the geographical distribution of fine dust across Britain: The annual mean concentration of PM2.5-dust in southern British air was roughly twice that of northern British air (in 2017: southern PM2.5: 10-20 $\mu \mathrm{g} / \mathrm{m}^{3}$; northern PM2.5: below $10 \mu \mathrm{g} / \mathrm{m}^{3}$; EEA Report 10/2019; similarly, PM10 by satellite: EEA 2005). This difference corresponds to the difference existing between higher densities of human population and industries in southern Britain, compared to lower densities in northern Britain. The area of gradual transition between the different densities of dust meets again the area along $54^{\circ}$ latitude, sketched by the axis Lancaster-York.

The evidence of these findings: Decline of insects can be absent, coinciding with concentration of fine dust (PM2.5) below $10 \mu \mathrm{g} / \mathrm{m}^{3}$.

In central Europe of last decades, Germany as paradigm, an annual mean concentration of PM2.5dust below $10 \mu \mathrm{g} / \mathrm{m}^{3}$ only occurred in few small, remote areas (at upper rivers Rhine and Inn: UBA 1, 2005-2010). The extensive studies of insect abundance, done in more central areas of Germany (Hallmann et al., 2017; Seibold et al., 2019), were associated with PM2.5-concentrations above 10 $\mu \mathrm{g} / \mathrm{m}^{3}$, similar to southern Britain (UBA 1, as before). These studies found severe decline of abundance of insects, reported above, similar to the findings of southern Britain. (Data on concentrations of fine dust corresponding to the earlier observations by Reichholf (Reichholf, 2017) are not available.)

For understanding effects caused by fine dust, knowledge of main traits of its occurrence is essential: In our countries, fine dust occurs in huge banks, like invisible lakes of fog, extending from few to hundreds of kilometers. These banks are not necessarily bound to industrialized or agricultural centers (UBA 2). They approach or suddenly arise, and their concentration of dust may change up to ten-fold or more within a few days and may oscillate (UBA 3). Thus, the local concentration at some site, effective for a period of days, may be manifold higher than the annual mean, i.e. the nominal concentration at that site.

If we associate recorded data of distribution of fine dust with the risk fine dust causes for the tracheal system of insects, as elucidated above, fine dust becomes apparent as potential driver of the acute decline of insects. Its estimated effects reveal characteristics of a driver of insect decline similar to those Seibold and colleagues recently found, which they described as acting "at larger spatial scale", "at landscape level" "independently of local land-use intensity" (Seibold et al., 2019). In a comprehensive study exerted for 11 years (2005-2015), Rada and colleagues compared the decline of richness of butterfly species inside versus outside of 245 nature protection areas distributed across Germany (Rada et al., 2019: 122 species of butterflies in Natura 2000 sites (EU-definition of protection)). They found the same factors of decline inside these areas as in $10 \mathrm{~km}$ distance outside ( $10 \%$ decline within 11 years) and ascribed these factors to unknown supra-regional drivers. Here, we try to understand these results by properties and influence of fine dust: The protected natural areas are as much object to floating fine dust as the unprotected areas are. In the years of study, the concentration of PM2.5 was above $10 \mu \mathrm{g} / \mathrm{m}^{3}$ in most regions of Germany (UBA 1); i.e., it was within the range of concentrations that in Britain occurred to be correlated with insect's declining.

Forest areas, different from grasslands, can be expected to bind some but not all of ultrafine dust that is included in the streaming air surrounding and infiltrating a forest. For insects that live within the forest area, these and preceding considerations predict a reduced probability to get affected by this dust, depending on density and extent of the forest. This prediction is in qualitative accordance with data collected by Seibold et al. (2019): For insects in and at forests they found decline similar 
but smaller than those found for insects at grassland sites; they "suggest that the drivers behind arthropod declines in forests also act at landscape-level spatial scales".

\section{- Consequences of endurance of pollution:}

If, for a population of insects, a load of dust remains the same during several years, its annual offspring will be continuously reduced by similar percentages per year. For successive generations, exponentially declining curves of population result. Curves approximating such description were found, e.g., for British moths by Conrad et al. (2006) studied for 35 years and, in Germany, for the collection of flying insects by Hallmann et al. (2017), studied for 27 years, and by Seibold et al. (2019) for 9 years.

Even at a drastically reduced level of density of a population at enduring pollution, no constancy of this level can be expected, since the inhaling of pollutants by individuals is independent from the density of the population. Only reduction of the pollution or - theoretically - a selection of more resistant individuals could cause a constant population density. For long-term development, this is a particularly serious aspect - and a major difference to ecologically systemic hazards, e.g. scarcity of food or predator-prey relations, in which new equilibria can emerge, since reduction of the density of individuals reduces danger to the remnants also.

\section{- Consequences of increased metabolic activity:}

Since $\mathrm{O}_{2}$-uptake per time is much higher during flight of insects than during their resting state (Jongbloed and Wiersma, 1934; see above), uptake of air pollutants during flight probably is higher by the same factor: i.e., in flying honeybees about 50 times higher than in their resting state. For collecting honeybees, a long flight within a region rich in fine dust, e.g. from human traffic, therefore may pose a particular timebound risk. It may be a cause for temporarily increased mortality of honeybees occurring in temporal relation to their collecting activity (e.g., phenomena like "colony collapse disorder", Oldroyd, 2007).

For those insect species for which a high proportion of flight activity is typical, such as hover flies, higher risk may exist than for species practicing less flight activity within the same area.

With similar causality, a higher percentage of damage can be expected for flight-active insects in activity-rich summer-months than in months with less flight activity. Data of the Krefeld collection correspond to this consequence: Most annual loss of flying insects occurred in months June to September, little loss in April (Hallmann et al., 2017: Fig. 2B).

Regardless of the season, the correlation existing between temperature and extent of flight activity could cause a correlation between increases of mean temperature (e.g. climate change) and probability of decline - a correlation that depends on the simultaneous particle concentration of fine dust (s. Lister and Garcia, 2018; Willig et al, 2019).

\section{- Consequences of different durations of generation cycle:}

Individuals of insect orders that are characterized by a short generation time, like many orders of flies, likely receive a smaller amount of fine dust per body weight during their individual life cycle than individuals of long-living species. Considering the populations in the range of years, however, this advantage should be compensated by their higher number of generations per year.

\section{- Consequences for stages of life in separated respiratory media: reduced endangerment of larval stages?}

In several orders of insects the residence time of individuals in open air is limited to few days of mating and reproductive processes, while their larval development, that often lasts for several years, is segregated from air either in fresh water with gas exchange by tracheal gills (Ephemeroptera, Plecoptera, Trichoptera, Odonata), or by soil, wood or bark filtering air (Coleoptera) (cf. SanchezBayo and Wyck-huys, 2019). Thus, they are protected from direct access of atmospheric hazardous 
substances for months or years, as long as the substances do not accumulate in the shielding material. Currently, a proliferation of bark beetles (Ips typographus), in spruce forests of Germany, indeed presents no indication of insect decline. The reproductive phase of such species, however, is of similar duration as that of species practicing a short overall generation time, such as flies.

\section{Conclusion II:}

The actual decline of insects may be understood by considering

- the physicochemical dirtiness of near-earth air including its irregular local changes of concentrations up to ten times,

- its effects on the microstructural respiratory processes in insects' organs,

- their dependence on the particular eco-physical and physiological conditions.

\section{Testing tracheal impairment and its consequences experimentally:}

It is a most urgent task to clarify fate and role of ultrafine dust invading the tracheolar system of insects. The author of this article can only offer suggestions:

Insect species that exert extensive flight activity provide most intensive exchange of gases:

a) Flies (Drosophila, Musca, Calliphora): intensive flight activity may be induced by stroboscopic flicker illumination between 50 and $100 \mathrm{~Hz}$ (own observation). Sources of fine dust: dust that contains fluorescing components; or air from busy urban thoroughfares.

b) Bee workers following collecting flights along busy highways.

\section{Questions arise for two key aspects:}

- Does ultra-fine dust accumulate in the tracheal system?

Are particles of airborne fine dust detectable in the body tissue of insects, depending on their metabolic activity (flight activity)? Can deposited dust be localized microscopically? At which sites?

\section{- Does human air pollution reduce insect's reproduction rates?}

Principle of experiments: Mobile cultures of Drosophila or Musca, may be used as "bio-probes" at sites of various air pollution; reference cultures kept at the same site, but perfused with defined clean air. The numbers of eggs or larvae produced per female are the parameter in question. Stimulation of motor activity of the animals is recommended. Test air pollution from a) intensive traffic, b) cattle or pig mass breeding. The experiment needs to allow identification of differences of fertility of few percent.

\section{Acknowledgements:}

For valuable discussions, corrections and textual improvements I am much indebted particularly to K.E. Kaissling and to R. Hertel, S. Luschnig, H. Berkefeld, J. Gödde, P. Görner, R. Thurm.

\section{Literature:}

Birmili W, Süring K, Becker K, Gerwig H, Schwirn K, Löschau G, Plaß D, Tobollik M (2018) Ultrafeine Partikel in der Umgebungsluft. - Aktueller Wissensstand. UMID (Umwelt und Mensch Informationsdienst)2/2018: 57-65.

Biserova N M, Pflüger H-J (2004) The ultrastructure of locust pleuroaxillary "steering" muscles in comparison to other skeletal muscles. Zoology 107: 229-242

Borash DJ, Pierce VA, Gibbs AG, Mueller LD (2000) Evolution of ammonia and urea tolerance in Drosophila melanogaster: resistance and cross-tolerance. J Insect Physiol 46: 763-769

Butler CG, Innes JM (1936) A comparison of the rate of metabolic activity in the solitary and migratory phases of Locusta migratoria. Proc Roy Soc [B] 119, 296-304 doi.org/10.1098/rspb.1936.0011 Chadwick LE, Gilmour (1940) Respiration during flight in Drosophila replete Wollaston: The oxygene consumption considered in relation to the wing-rate. Physiol Zool 13: 398-410

Conrad KF, Warren MS, Fox R, Parsons MS, Woiwod IP (2006) Rapid declines of common, widespread British moths provide evidence of an insect biodiversity crisis. Biol. Conserv. 132: 279-291. 
EEA 2005: http://www.esa.europa.eu/publications/spatial-assessment-of-pm-10-and-ozoneconcentrations-in-europe-2005-1/at

EEA Report 10/2019: European Environment Agency: www.eea.europa.eu/publications/air-qualityin-europe-2019/air-quality-in-europe-2019/viewfile\#pdfjs.action p. 30

Fox, Richard et 5 al., 2013. The State of Britain's Larger Moths 2013. Technical Report: www.researchgate.net/publication/273453430

German Federal Environment Agency (2017) Particulate matter pollution; benzoapyren; ammonia Hallmann CA, Sorg M, Jongejans E, Siepel H, et 10 al. (2017) More than 75 percent decline over 27 years in total flying insect biomass in protected areas. PLoS ONE 12 (10): e0185809.

doi./10.1371/journal.pone.0185809

Harrison JF (2009) „Tracheal System” in: Encyclopedia of Insects. p. 1011-1014

Herrenbauer M (2002) Biosorption von polyzyclischen aromatischen Kohlenwasserstoffen (PAK) an Mikroorganismen und Liposomen. Shaker Verlag, Aachen

Jongbloed J, Wiersma CAG (1934) Der Stoffwechsel der Honigbiene während des Fliegens. Z vergl Physiol 21: 519-533

Lister, B.C., Garcia, A. (2018) Climate-driven declines in arthropod abundance restructure a rainforest food web. doi/10.1073/pnas.1722477115

Marshall T A, Wood R W (1990) Ionic and osmotic regulation by larvae of the sheep blowfly Lucilia cuprina. J Insect Physiol 36 635-639

Oldroyd, B.P. (2007) What's killing American honeybees? PLos Biol 5(6)

Rada S, Schweiger O, Harpke A, et al. (2019) Protected areas do not mitigate biodiversity declines: A case study on butterflies. Divers Distrib. 25:217-224. https://doi.org/10.1111/ddi.12854

Reichholf JH (2017) „Das Verschwinden der Schmetterlinge“ 71 p. Deutsche Wildtier Stiftung, Hamburg

Sauerwald J, Backer W, Matzat T, Schnorrer F, Luschnig S (2019) Matrix metalloproteinase 1 modulates invasive behavior of tracheal branches during entry into Drosophila flight muscles. eLife 2019;8:e48857. DOI: https://doi.org/10.7554/eLife.48857

Schmidt K G, Zellner R (2010) Feinstaub Statuspapier. DECHEMA, Frankfurt/M.

Seibold, S., 18 further authors (2019) Arthropod decline in grasslands and forests is associated with landscape-level drivers. Nature 574: doi.org/10.1038/s41586-019-1684-3

UBA 1 (2020) http://gis.uba.de/Website/luft/index.html

UBA 2 (2020)_https://www.umweltbundesamt.de/en/data/air/air-

data/maps/eJxrXZScv9BwUXEykEhJXGVkYGSga2Cua2C5qCQTJF7OAADzHAzy

UBA 3 (2020)

https://www.umweltbundesamt.de/daten/luft/luftdaten/stationen/eJzrXpScv9BwUXEykEhJXGVkYGS ga2Cma2S8qCRzkaHxorzUBYuKSxabmRksSUIOKwIqMDQDKTAwBPJD8qF8c11jw0XJiZPbCJhWXLLEOML YaFFZIg8xSiONQUr5CCsFuQ-oUmBRbhX3otzkpsU5iSWnHTz9X1jOX_JocU5e-mkH9U2Wz8yMAAAE9FCAQ==

Weihrauch D, Donini A, O’Donnell M (2012) Ammonia transport by terrestrial and aquatic insects. J. Insect Physiol. 58: 473-487

Wigglesworth VB (1983) The Physiology of Insect Tracheoles. Advances Insect Physiol. 17: 85-148

Wigglesworth VB (1984) Insect Physiology. Chapman and Hall, London

Willig MR, Woolbright L, Presley SJ, Schowalter TD, Waide RB, Heartsill Scalley T, Zimmerman JK, Gonzalez G, Lugo AE (2019) Populations are not declining and food webs are not collapsing at the Luquillo experimental forest. PNAS 116, 12143-12144

Würgler FE, Ramel C, Moustacchi E, Carere A (1986) Assays for genetic activity in Drosophila melanogaster. In: Montesano R et al. (Eds.) Long-term and short-term assays for carcinogens: A critical appraisal, Vol. 83, IARC Sci. Publ., Lyon. Pp. 351-393 